\title{
Knowledge, Attitudes and Practices (KAP) about Refractive Error among Students Attending Faculty of Health Sciences at Lúrio University in Mozambique, 2020
}

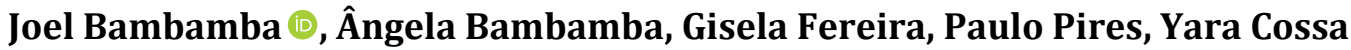 \\ Faculty of Health Sciences, Lúrio University, Nampula, Mozambique \\ Email: jbambamba@unilurio.ac.mz
}

How to cite this paper: Bambamba, J., Bambamba, Â., Fereira, G., Pires, P. and Cossa, Y. (2022) Knowledge, Attitudes and Practices (KAP) about Refractive Error among Students Attending Faculty of Health Sciences at Lúrio University in Mozambique, 2020. Open Journal of Ophthalmology, 12, 57-69.

https://doi.org/10.4236/ojoph.2022.121007

Received: October 3, 2021

Accepted: February 7, 2022

Published: February 10, 2022

Copyright $\odot 2022$ by author(s) and Scientific Research Publishing Inc. This work is licensed under the Creative Commons Attribution International License (CC BY 4.0).

http://creativecommons.org/licenses/by/4.0/

\begin{abstract}
Introduction: Refractive error is recognized as one of the most important causes of correctable visual impairment and affects people of all ages, socioeconomic levels, and ethnic groups. The World Health Organization (WHO) estimated 285 million people globally were visually impaired, with 39 million blinds. The aim of this study is to access the knowledge, attitudes, and practices of health sciences students about the refractive error in Nampula, Mozambique. Material and Methods: Descriptive cross-sectional study including health sciences students of Lúrio University in Nampula, applying a questionnaire to access their knowledge, attitudes, and practices concerning the refractive error. The collected data were entered into SPSS version 22.0 for analysis. Frequency distribution and central tendency measures (mean, median) were used to summarize the descriptive part of the study. Results were described using tables and running text. Sample students were included after obtaining informed consent. Results: A total of 298 students participated in the study, 50.3\% female, with average age of $24 \pm 5.4$ years. $69.8 \%$ had an eye exam and $54.7 \%$ believe they have good vision, $58.1 \%$ say that wearing glasses is the main method of correcting refractive errors. $92.3 \%$ refer to the Central Hospital as the best place to provide eye health services. The main reason for not purchasing the glasses was their cost (47.3\%) and the alternative method for spectacle users was contact lenses (81.0\%). The students' attitudes were positive towards the use of glasses. Conclusion: Visual health education about the knowledge, attitudes and practices regarding refractive errors among students must be intensified to ensure good dissemination of information in the surrounding communities enrolled in the health promotion program "One Student, One Family" implemented by Lúrio University in Nampula.
\end{abstract}




\section{Keywords}

Knowledge, Attitude, Practice, Refractive Error, Students

\section{Introduction}

The high prevalence of significant refractive error and the costs associated to correct it, with glasses, contact lenses or surgery, are strong economic and public health concerns [1].

Refractive errors are one of the main causes of visual impairment worldwide $(43 \%)$, and uncorrected refractive error represents more than half of the causes of visual impairment and $18.2 \%$ of blindness [2].

Globally, more than 2.3 billion people suffer from refractive error-related poor vision; however, refractive error can simply be detected, diagnosed, measured, and subsequently corrected using optical corrective approaches and devices such as eyeglasses and contact lenses or surgical procedures [3].

According to global surveys, most people with uncorrected refractive errors are in rural areas and low-income countries, the majority in Africa. Regardless of age, gender and ethnicity, refractive errors if not corrected, will result in decreased quality of life for millions of people around the world [4].

The school is a reference centre not only in education, but also in health care and promotion, concentrating on community actions [5]. University students have the capacity to express and declare their symptoms more properly, as well as to be more independent [6].

However, it is necessary to attain the correct level of knowledge, to promote a change in health practices and attitudes, within schools and communities, valuing primary care, about refractive errors [7].

Globally, the economic loss due to lost productivity caused by uncorrected refractive errors was estimated to be around $\$ 269$ billion and due to uncorrected presbyopia was $\$ 11.023$ billion [8]. The exercise of estimating trends in the global burden of blindness and visual impairment is important for understanding areas of unmet need and for improving vision health policy planning and prioritization; however, the lack of professionals with specific training, experience, and equipment in low- and middle-income countries restricts the exploration of visual impairment and blindness [9]. There is no evidence to show the knowledge, attitudes and practices of refractive errors in Mozambique as well as the study area among university students.

The interest in students of the Health Science Faculty of Lúrio University is expressed in the fact that they are exposed since the first semester in a community health promotion program "One Student, One Family", where they work in multidisciplinary groups to exchange information with the community.

This study was designed to determine the Knowledge, Attitudes and Practices (KAP) regarding refractive error among students attending health sciences fac- 
ulty at Lúrio University in Nampula. Ultimately, this study will also serve as baseline information for those who want to explore further to assess the KAP of refractive error in primary school teachers, parents/guardians and communities enrolled by the "One Student, One Family" program.

\section{Material and Methods}

From March 24th to April 26th, 2020, we applied a KAP survey among university students enrolled in health sciences courses of Medicine, Dentistry, Pharmacy, Nutrition, Optometry and Nursing of a public university in Nampula city. It is a descriptive cross-sectional study in a universe of 1310 students. All students of health sciences faculty (from the first to sixth year) who were available during the study period were eligible to be included in the study.

This study was approved by the Lúrio University Institutional Ethical Review Board. Consent was obtained from participants. The study followed all Helsinki Declaration (2013) recommendations. Written informed consent was obtained from each study participant. Participants were informed about the objective of the study and they were given full right to discontinue or refuse to participate in the study.

The sample size was calculated based on the unknown prevalence for KAP (50\%), with $\mathrm{z}=1.96$, for a population of 1310 students in the Faculty of Health Sciences at Lúrio University, considering a significance level of 5\% and 95\% confidence interval and the final estimated sample size was 298.

A questionnaire of 19-item questions adapted from earlier studies done in a similar population was developed. The questionnaire was translated to Portuguese. Therefore the back translation was performed to ensure language equivalence between the English and Portuguese versions of the scale (see Appendix 1).

Four experts (Three optometrists and one medical doctor specialized in Family medicine) provided opinions about meaning and content sufficiency. A pilot study Performed with 20 Students of a similar population was then conducted from 5 - 12 March 2021 to determine whether there were any unclear questions in the scale. The data from the pilot study were then excluded from the final data analysis.

The Cronbach's test was applied to determine internal consistency and uniformity, with value of 0.801 .

Each participant completed a self-administered questionnaire to obtain demographic data and determine their Knowledge, Attitude and Practice (KAP) towards refractive error. The data was analyzed using SPSS 22.0. Frequency distribution and central tendency measures (mean, median) were used to summarize the descriptive part of the study. The median Likert scale was computed and used to identify the majority opinion to questions regarding correction of refractive error using spectacles.

Knowledge on the student's current status of vision and accessibility of eye healthcare facilities was asked. 
Attitudes towards spectacle use were scored on five-point Likert scale ( $1=$ strongly disagree, 2 = disagree, $3=$ neutral, $4=$ agree, $5=$ strongly agree) using 8 questions, and the score points ranged from 8 to 40 .

Attitude about refractive errors were categorized as positive attitude for participant who answered the median score (17.8) and above of the attitude-related questions and negative attitude, whereas those participants who answered less than the median score.

\section{Results}

\subsection{Socio-Demographic Characteristics of the Sample}

Information regarding gender, age and Course is summarized in Table 1. A total of 298 students completed the questionnaire. Regarding distribution by gender, there were $150(50.3 \%)$ female and $148(49.7 \%)$ males, a ratio 1.01 . The average age was $24 \pm 5.4$ years. Pharmacy students had greater participation with $65(21.8 \%)$, Optometry with 56 (18.8\%), Nutrition with 55 (18.5\%), Medicine with 51 (17.1\%), Nursing with 38 (12.8\%) and Dentistry with 33 (11.1\%) students respectively.

\subsection{Knowledge about Refractive Error}

- The information about knowledge of refractive error was assessed and summarized in Table 2.

Table 1. Distribution according to the socio-demographic characteristics of the sample.

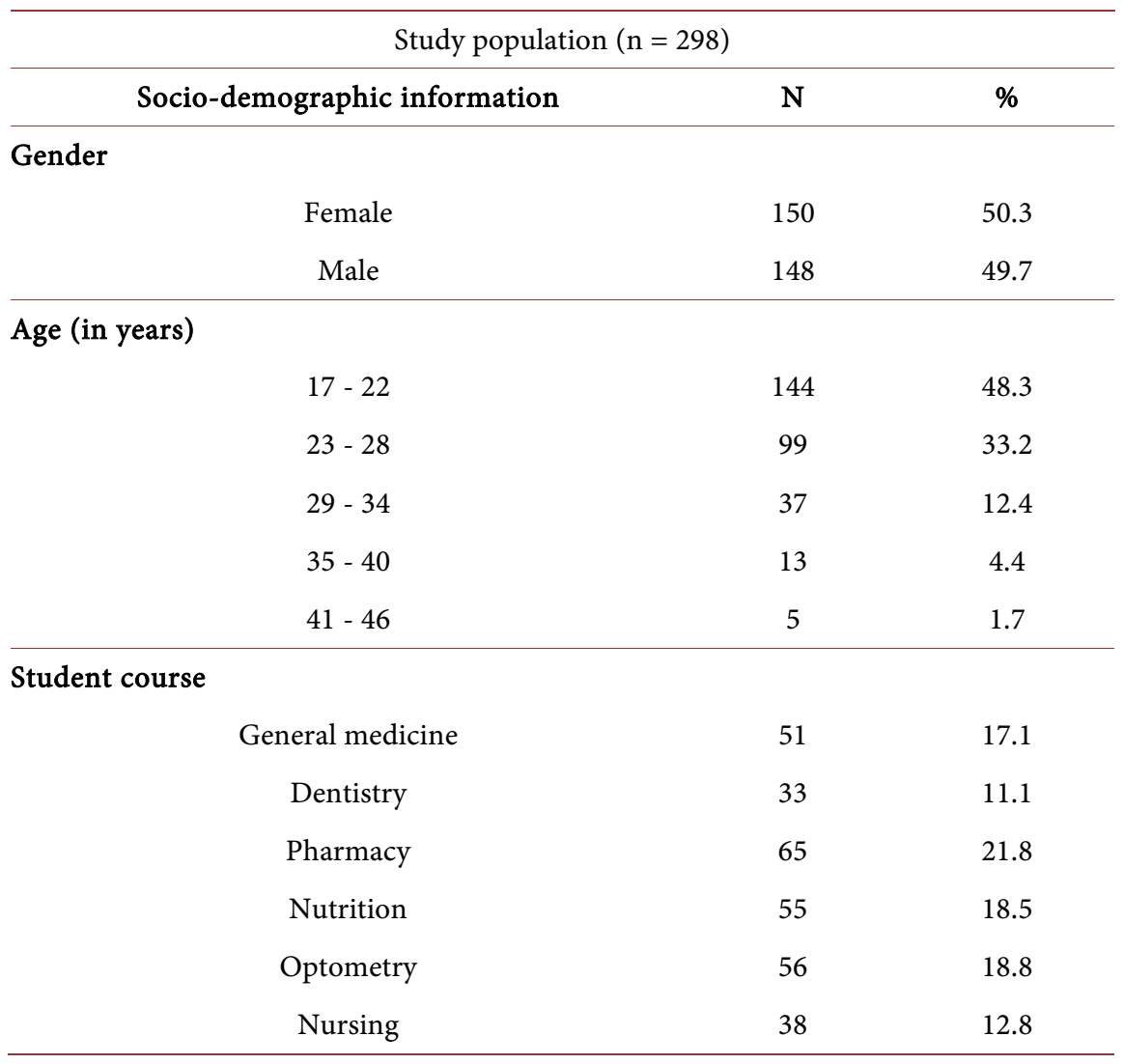


Table 2. Participants knowledge about refractive error.

\begin{tabular}{|c|c|c|c|}
\hline \multicolumn{4}{|c|}{ Size of study population $(n=298)$} \\
\hline \multicolumn{4}{|c|}{ 1. Knowledge about current refractive state } \\
\hline \multicolumn{2}{|c|}{ Have you ever had an eye exam? } & \multicolumn{2}{|c|}{ Do you think you have good eyesight? } \\
\hline Yes & $208(69.8 \%)$ & Yes & $163(54.7 \%)$ \\
\hline \multirow[t]{2}{*}{ No } & $90(30.2 \%)$ & No & $70(23.5 \%)$ \\
\hline & & Don't know & $65(21.8 \%)$ \\
\hline \multicolumn{4}{|c|}{ 2. Knowledge about the methods of correction of refractive errors } \\
\hline \multicolumn{4}{|c|}{ What methods for correcting refractive errors do you know? } \\
\hline & Surgery & $29(9.7 \%)$ & \\
\hline & lenses & $25(8.4 \%)$ & \\
\hline oph & ic lenses & $173(58.1 \%)$ & \\
\hline & ation & $52(17.4 \%)$ & \\
\hline & swer & $19(6.3 \%)$ & \\
\hline
\end{tabular}

- Regarding the understanding about current refractive state 208 (69.8\%) out of 298 students had a previous eye exam and $163(54.7 \%)$ think they have good eyesight.

- About knowledge regarding methods to correct refractive errors, 173 (58.1\%) students appointed ophthalmic lenses, 52 (17.4\%) appointed medication, 29 (9.7\%) appointed surgery and 25 (8.4\%) Contact lenses.

\subsection{Students' Practice Regarding Refractive Error}

- To access students' practice regarding refractive errors, questions were modelled towards the accessibility and barriers of eye care services. The Whole information is illustrated in Table 3.

- Students were questioned about where to seek for help in case of vision problems: 144 (52.4\%) mentioned Central Hospital, 98 (35.6\%) optical shops and $33(12.0 \%)$ health care centres. Most students who had a previous eye exam accessed it in an optical shop (117, 56.3\%), 65 (31.3\%) at central hospital and 26 $(12.5 \%)$ at a health centre.

- 129 (62.0\%) reported having been prescribed eyeglasses; 75 (58.1\%) of these students had their glasses at the time they filled out the questionnaire; 54 students reported the main reason why they were no wearing: $70.4 \%$ due to cost of eyeglass preventing purchase, $13.0 \%$ had broken their glasses, $5.6 \%$ lost their prescription, $3.7 \%$ mentioned headaches with their glasses and $1.9 \%$ said they didn't notice any difference with the glasses.

\subsection{Attitudes towards Refractive Error in Lúrio University Students}

- Regarding attitude towards refractive error, all Information is gathered in Figure 1, study participants strongly disagreed: 191 (64.1\%) with the opinion 
that young people do not need correction for refractive errors; 143 (48.0\%) with the common myth that glasses damage the eyes; 93 (31.2\%) with the statement "glasses lead to dependence and deterioration of vision".

Table 3. Participants practice about refractive error.

$$
\text { Size of study population }(\mathrm{n}=298)
$$

\section{Access to eye health care}

Do you know where to seek for help if you have vision problems?

$$
\begin{array}{cc}
\text { Yes } & 275(92.3 \%) \\
\text { No } & 23(7.7 \%)
\end{array}
$$

Where should you seek? $(\mathrm{n}=275)$

$$
\begin{array}{cc}
\text { Health care centre } & 33(12.0 \%) \\
\text { Central hospital } & 144(52.4 \%) \\
\text { Optic shop } & 98(35.6 \%)
\end{array}
$$

Where did you have the eye exam? $(\mathrm{n}=208)$

$\begin{array}{cc}\text { Health care centre } & 26(12.5 \%) \\ \text { Central hospital } & 65(31.3 \%) \\ \text { Optic shop } & 117(56.3 \%)\end{array}$

\section{Barriers for the use of spectacles}

Have you ever been prescribed glasses? $(n=208)$

$\begin{array}{lc}\text { Yes } & 129(62.0 \%) \\ \text { No } & 79(38.0 \%)\end{array}$

Do you have the glasses? $(\mathrm{n}=129)$

$\begin{array}{ll}\text { Yes } & 75(58.1 \%) \\ \text { No } & 54(41.9 \%)\end{array}$

Why don't you have the prescribed glasses? $(n=54)$

$\begin{array}{cc}\text { It doesn't make any difference } & 1(1.9 \%) \\ \text { I feel headaches } & 2(3.7 \%) \\ \text { they are very expensive } & 38(70.4 \%) \\ \text { I lost the prescription } & 3(5.6 \%) \\ \text { I broke my glasses } & 7(13.0 \%) \\ \text { No answer } & 3(5.6 \%)\end{array}$

\section{Alternative methods for correction of refractive error}

Would you like to try another way to correct your vision? $(\mathrm{n}=75)$

$\begin{array}{ll}\text { Yes } & 21(28.0 \%) \\ \text { No } & 54(72.0 \%)\end{array}$

Which method would you like to try? $(\mathrm{n}=21)$

Refractive surgery $\quad 4(19.0 \%)$
Contact lenses
$17(81.0 \%)$ 


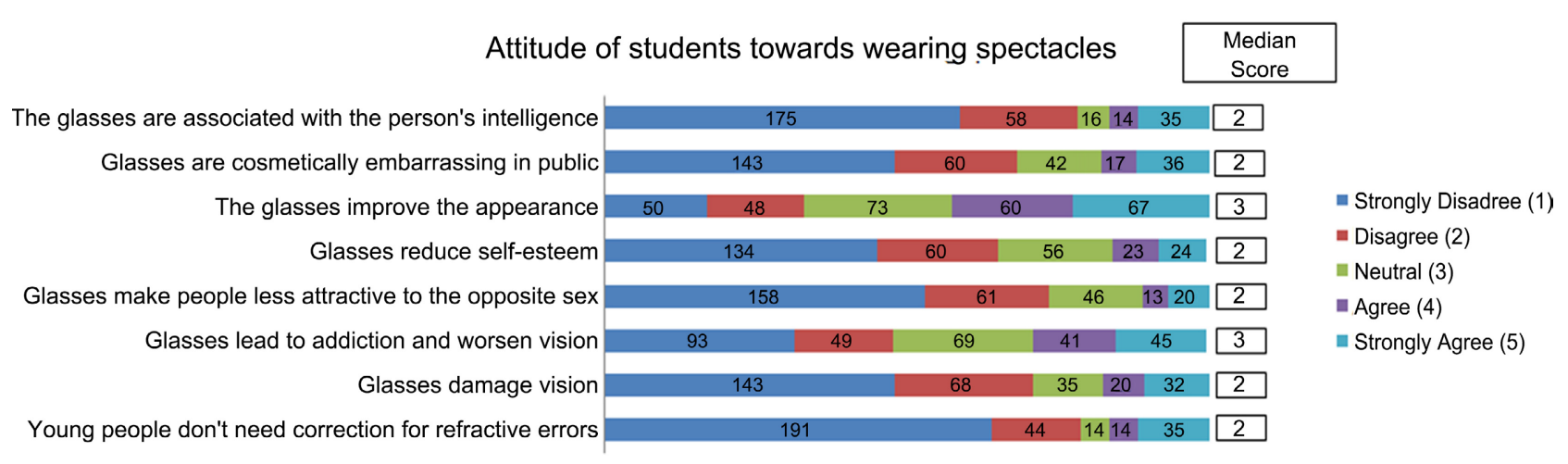

Figure 1. Students' attitudes towards spectacle wear.

- When mentioned that glasses make people less attractive to the opposite sex, $158(53.0 \%)$ students strongly disagree and 134 (45.0\%) strongly disagree glasses lead to reduced self-esteem.

- About appearance improvement, 76 (16.1\%) students are neutral; 143 (48.0\%) strongly disagree that glasses are cosmetically embarrassing or unacceptable to the public; 175 (58.7\%) totally disagree that glasses are associated with intelligence.

- The results towards attitude of spectacle use demonstrated that 149 (50\%) of the students scored equal or above the median and the other 149 (50\%) scored less than the median.

\section{Discussion}

In the present study, we found that regarding the knowledge about the current refractive state, $69.8 \%$ had a previous eye exam which is not consistent with the study done by Nyamai et al. (39.0\%) when evaluating Knowledge, attitude and practice on refractive error among students attending public high schools in Nairobi County, Kenya [3].

Routine eye examinations are important for the timely detection and management of vision issues. As the major causes of Visual Impairment (VI) and blindness are treatable, appropriate use of eye care services, such as regular eye examinations, is a key factor in optimizing national eye health [10].

However, there are several factors that may act as barriers to the use of available, accessible, and affordable eye care services such as the lack of knowledge of the services, of the possible impact of an eye disease or who to consult for management of eye diseases. Also, demographic, personal, social, and cultural factors may influence or act as barriers to eye care services [11]. The fact that the most participant students had a previous eye exam is also consistent with the fact that Lúrio University has an Optometry degree and an eye care centre serving the population, where students practice, and as part of university social responsibility to the nearby communities.

This study found that the majority of students (58.1\%) mentioned ophthalmic lenses (glasses) as a method of refractive error correction. This result is not in 
agreement with the study performed by Ebeigbe et al. which found 38.0\% [12].

Spectacles are the most used form of refractive error correction since they are the most inexpensive and the simplest of the three options of correcting refractive error; so, they are the most appropriate treatment for refractive errors in developing countries, but provision of spectacles is currently a challenge in many of those countries, due to availability and affordability issues [13].

In many areas of the world spectacles are either not available or are too expensive. While having adequately trained practitioners is essential to provide refraction and eye care to communities, this care must be supported with the devices needed to restore sight. The challenge now is to develop ways of supplying good quality spectacles to communities in need [14].

From the 275 (92.3\%) who claimed to know where to look for help, 144 (52.4\%) mentioned a general/central hospital; controversially 177 (56.3\%) out 208 students who reported having had an eye exam, referred an optical shop to do it. Even when eye health services are provided at no cost, not all patients choose to access them. In some instances, people with eye health needs may be unaware of free or subsidized services. A lack of information about the service may be as much of a barrier as cost. The significance of cost as a barrier may change with time [15]-[20].

The 2019 World Report on Vision calls for the advancement of eye health through integration into Universal Health Coverage, with an emphasis on strengthened services within primary health care. Primary care for eye-related ailments is delivered using different approaches, including via primary health-care staff trained in basic eye care delivered at fixed community-based facilities or via occasional outreach clinics by a specialist eye care team to primary health-care facilities [21] [22] [23].

In the present study, the overall attitude towards spectacle use was (50.0\%). This finding is slightly similar to that found by Assefa et al. (52.1\%) when evaluating Knowledge and Attitude of Refractive Error among Public High School Students in Gondar City, Ethiopia [24].

Out of the total study participants, $17.4 \%$ of students disagree with the fact that glasses damage the eyes, a lower percentage than the study done in Sudan (36.4\%) [25]. A small group of participants (16.4\%) agree that young people with refractive errors need spectacle for correction, which is a much lower percentage than those found in the study performed in Saudi Arabia (67.7\%) [26].

\section{Limitation and Strength of the Study}

The use of non-probabilistic sampling limits the extrapolation and generalization of results. Other potential determinants of refractive error knowledge were not evaluated in this research. Questions about the definition of refractive error and its causes were initially included, but due to participant's responses bias in questionnaire pretesting, they were not included. This research strength includes the low cost of survey and offers a basic protocol design for other studies with 
different subjects (parents, guardians, schoolteachers, health professionals).

\section{Conclusion}

The knowledge, attitudes and practices about refractive errors and correction methods, within the health sciences students at Lúrio University, are encouraging. They showed a good level of knowledge about their refractive error status and correction methods, especially for ophthalmic lenses. Although the students mentioned a general hospital or a primary health centre to seek for help when having an eye problem, most of them had the eye exam in an optic shop. The existence of an optometry degree and an eye care centre in the Lúrio University campus also played an influence towards the knowledge and attitude of the students about the refractive errors. Moreover, the students are exposed since the first semester in a community health promotion program "One Student, One Family", when they work in multidisciplinary groups to exchange information with the community. This study shows it is important to intensify the dissemination of information and education activities about the refractive errors, to consolidate and optimize information to promote eye and vision health behaviours.

\section{Acknowledgements}

The authors thank Lúrio University, Faculty of Health Sciences for approval to conduct this research. We would also like to acknowledge the study participants for their cooperation and willingness during data collection.

\section{Conflicts of Interest}

The authors declare they have no conflicts of interest.

\section{References}

[1] Irving, E.L., Machan, C.M., Lam, S., Hrynchak, P.K. and Lillakas, L. (2019) Refractive Error Magnitude and Variability: Relation to Age. Journal of Optometry, 12, 55-63. https://doi.org/10.1016/j.optom.2018.02.002

[2] Desalegn, A., Tsegaw, A., Shiferaw, D. and Woretaw, H. (2016) Knowledge, Attitude, Practice and Associated Factors towards Spectacles Use among Adults in Gondar Town, Northwest Ethiopia. BMC Ophthalmology, 16, Article No. 184. https://doi.org/10.1186/s12886-016-0357-3

[3] Nyamai, L.A., Kanyata, D., Njambi, L. and Njuguna, M. (2016) Knowledge, Attitude and Practice on Refractive Error among Students Attending Public High Schools in Nairobi County. Journal of Ophthalmology of Eastern Central and Southern Africa, 20, 33-39.

[4] Chawla, K. and Rovers, J. (2009) Survey of Patient Opinions on Eyeglasses and Eye Care in Rural and Slum Populations in Chennai. The Internet Journal of Epidemiology, 8, 1-7.

[5] Carvalho, A.S.B. (2013) Prevalência dos Erros Refrativos em Portugal Usando Informação Proveniente da Venda de Receituário, Dissertação de Mestrado Mestrado em Optometria Avançada, Abril 2013.

[6] Carvalho, G.F., et al. (2015) A importância do teste de acuidade visual na idade 
escolar. Revista Investigação, 14, 56-72.

[7] Oliveira, R.S., Parizotto, A.V., Caleffi, M.F., Beal, C., Yeh, W.S.S. and Vicensi, M.C. (2013) Avaliação da acuidade visual em escolares no município de Herval d'Oeste, Santa Catarina, Brasil. Revista Brasileira de Medicina de Família e Comunidade, 8 , 180-186.

[8] Sheeladevi, S., Seelam, B., Nukella, P.B., Borah, R.R., Ali, R. and Keay, L. (2019) Prevalence of Refractive Errors, Uncorrected Refractive Error, and Presbyopia in Adults in India: A Systematic Review. Indian Journal of Ophthalmology, 67, 583-592. https://doi.org/10.4103/ijo.IJO 123518

[9] Kahloun, R., Khairallah, M., Resnikoff, S., Cicinelli, M.V., Flaxman, S.R., Das, A., et al. (2019) Vision Loss Expert Group of the Global Burden of Disease Study. Prevalence and Causes of Vision Loss in North Africa and Middle East in 2015: Magnitude, Temporal Trends and Projections. British Journal of Ophthalmology, 103, 863 870. https://doi.org/10.1136/bjophthalmol-2018-312068

[10] Gupta, P., Majithia, S., Fenwick, E.K., Gan, A.T.L., Tham, Y.-C., Poh, S., Thakur, S., Sabanayagam, C., Wong, T.Y., Cheng, C.-Y. and Lamoureux, E.L. (2020) Rates and Determinants of Eyecare Utilization and Eyeglass Affordability among Individuals with Visual Impairment in a Multi-Ethnic Population-Based Study in Singapore. Translational Vision Science \& Technology, 9, Article No. 11. https://doi.org/10.1167/tvst.9.5.11

[11] Ntsoane, M.D. and Oduntan, O.A. (2010) A Review of Factors Influencing the Utilization of Eye Care Services. South African Optometrist, 69, Article No. a43. https://doi.org/10.4102/aveh.v69i4.143

[12] Ebeigbe, J.A., Kio, F. and Okafor, L.I. (2013) Attitude and Beliefs of Nigerian Undergraduates to Spectacle Wear. Ghana Medical Journal, 47, 70-73.

[13] Omolase, C.O. and Mahmoud, A.O. (2009) Factors Associated with Non-Compliance with Spectacle Wear in an Adult Nigerian Population. African Journal of Biomedical Research, 12, 43-46.

[14] Holden, B.A., Sulaiman, S. and Knox, K. (2000) The Challenge of Providing Spectacles in the Developing World. Community Eye Health, 13, 9-10.

[15] Keeffe, J.E., Weih, L.M., McCarty, C.A. and Taylor, H.R. (2002) Utilisation of Eye care Services by Urban and Rural Australians. British Journal of Ophthalmology, 86, 24-27. https://doi.org/10.1136/bjo.86.1.24

[16] Dandona, R., Dandona, L., Naduvilath, T.J., McCarty, C.A. and Rao, G.N. (2000) Utilisation of Eyecare Services in an Urban Population in Southern India: The Andhra Pradesh Eye Disease Study. British Journal of Ophthalmology, 84, 22-27.

https://doi.org/10.1136/bjo.84.1.22

[17] Thompson, S., Naidoo, K., Gonzalez-Alvarez, C., Harris, G., Chinanayi, F. and Loughman, J. (2015) Barriers to Use of Refractive Services in Mozambique. Optometry and Vision Science, 92, 59-69. https://doi.org/10.1097/OPX.0000000000000431

[18] Crews, J.E., Chou, C.F., Zack, M.M., Zhang, X., Bullard, K.M., Morse, A.R. and Saaddine, J.B. (2016) The Association of Health-Related Quality of Life with Severity of Visual Impairment among People Aged 40-64 Years: Findings from the 2006-2010 Behavioral Risk Factor Surveillance System. Ophthalmic Epidemiology, 23, 145-153. https://doi.org/10.3109/09286586.2016.1168851

[19] Crews, J.E., Chou, C.F., Zhang, X., Zack, M.M. and Saaddine, J.B. (2014) Health-Related Quality of Life among People Aged $\geq 65$ Years with Self-Reported Visual Impairment: Findings from the 2006-2010 Behavioral Risk Factor Surveillance System. Ophthalmic Epidemiology, 21, 287-296. https://doi.org/10.3109/09286586.2014.926556 
[20] Pang, Y., Ren, Z. and Wang, J. (2020) Impact of the Affordable Care Act on Utilization of Benefits of Eye Care and Primary Care Examinations. PLOS ONE, 15, Article ID: e0241475. https://doi.org/10.1371/journal.pone.0241475

[21] World Health Organization (2019) World Report on Vision. World Health Organization, Geneva.

[22] Misra, V., Vashist, P., Malhotra, S. and Gupta, S.K. (2015) Models for Primary Eye Care Services in India. Indian Journal of Community Medicine, 40, 79-84. https://doi.org/10.4103/0970-0218.153868

[23] Rono, H., Bastawrous, A., Macleod, D., Mamboleo, R., Bunywera, C., Wanjala, E., et al. (2021) Effectiveness of an mHealth System on Access to Eye Health Services in Kenya: A Cluster-Randomised Controlled Trial. Lancet Digital Health, 3, e414-e424. https://doi.org/10.1016/S2589-7500(21)00083-2

[24] Assefa, N.L., Tegegn, M.T. and Wolde, S.Y. (2021) Knowledge and Attitude of Refractive Error among Public High School Students in Gondar City. Clinical Optometry, 13, 201-208. https://doi.org/10.2147/OPTO.S322438

[25] Alswailmi, F., Mohamed, A., Gomma, S., Khalafallah, H. and Mohamed, H. (2018) Attitude of Female Undergraduates towards Spectacle Correction of Refractive Errors. COJ Nursing \& Healthcare, 4, 422-426.

[26] Dhoble, P., Agarwal, R., Patel, C., Anand, G., Sharma, J. and Sabde, Y. (2013) Study to Assess the Psychosocial Aspects of Refractive Errors and Effectiveness of Health Education in Correcting Stigmas Related to Spectacle Use in High-School Students of Rural India. International Journal of Medical Science and Public Health, 2, 716-719. https://doi.org/10.5455/ijmsph.2013.060520131 


\section{Appendix 1}

Questionnaire

\section{Confidential for Research Purpose Only}

Knowledge, Attitude and Practice about Refractive Error among Health Science Faculty Students of Lurio University in Mozambique, 2021.

Gender

$\mathrm{M} \square$

$\mathrm{F} \square$

Age (Years) $\square$

Course

\section{Knowledge about refractive error}

Have you ever had an eye exam?

Yes $\square \quad$ No

Do you think you have good eyesight?

Yes

No

What methods for correcting refractive errors do you know?

Surgery

Contact lenses

Ophthalmic lenses

Medication

Access to eye health care

Do you know where to seek for help if you have vision problems?

Yes

No

If yes, where should you seek for help when having eye problem?

Health care centre

Central hospital

Optic shop

Where did you have the eye exam?

Health care centre

Central hospital

Optic shop

\section{Barriers for the use of spectacles}

Have you ever been prescribed glasses? Yes $\square \quad$ No $\square$

If yes, do you have the glasses?

Yes $\square \quad$ No

Why don't you have the prescribed glasses?

It doesn't make any difference $\square$

I feel headaches

They are very expensive

I lost the prescription

I broke my glasses

How often do you wear glasses?

Always

Sometimes

\section{Alternative methods for correction of refractive error}

Would you like to try another way to correct your vision? Yes

Which method would you like to try?

Refractive Surgery

Contact Lenses 


\section{Attitude of students towards spectacle use}

For the following items, we ask you to mark only one number that corresponds to your answer, as follows: 1 . Strongly disagree; 2. I disagree; 3. Neutral; 4. Agree; 5. Strongly Agree

The glasses are associated with the person's intelligence

$\begin{array}{llllll}1 & 2 & 3 & 4 & 5\end{array}$

Glasses are cosmetically embarrassing in public

$\begin{array}{lllll}1 & 2 & 3 & 4 & 5\end{array}$

The glasses improve the Appearance

$\begin{array}{cc}2 & 3 \\ \text { Glasses reduce self-esteem }\end{array}$

$\begin{array}{llllll}1 & 2 & 3 & 4 & 5\end{array}$

Glasses make people less attractive to the opposite sex

$\begin{array}{lllll}1 & 2 & 3 & 4 & 5\end{array}$

Glasses damage the vision

$\begin{array}{lllll}1 & 2 & 3 & 4 & 5\end{array}$

Young people don't need correction for refractive errors

2

3

4

5

Glasses lead to addiction and worsen vision 